УДК 537.874 .6

\title{
ОПРЕДЕЛЕНИЕ ПОЛОЖЕНИЯ И ОРИЕНТАЦИИ ПРОВОДЯЩЕГО СТЕРЖНЯ С ПОМОЩЬЮ НЕЙРОННОЙ СЕТИ
}

\author{
ЛЯСОТА Д. В. ${ }^{1}$, МОРОЗОВ в. М. ${ }^{1}$, СъЯНОВ А. М. ${ }^{2}$ \\ ${ }^{1}$ Днепропетровский национальный университет им. О.Т. Гончара, \\ Украина, Днепропетровск, 49050, ул. Научная, 13 \\ 2 Днепродзержинский государственный технический университет, \\ Украина, Днепродзержинск, 51900, Днепростроевская 2
}

\begin{abstract}
Аннотация. Методом интегрального уравнения решена задача дифракции электромагнитной волны на проводящем стержне. Построена диаграмма обратного рассеивания. Проведено вейвлет-пакетное разложение полученной характеристики. На основании значений энтропии Шеннона компонентов разложения построен вектор признаков. Обучена нейронная сеть на основе радиальных базисных элементов, позволяющая определить положение стержня и его пространственную ориентацию на основании вектора признаков. Проведено численное моделирование и статистический анализ результатов расчета
\end{abstract}

Ключевые слова: метод интегрального уравнения; дифракция на металлическом стержне; вейвлет-пакетное преобразование; нейронная сеть; радиальный базисный элемент

\section{ВВЕДЕНИЕ}

Нейронные сети хорошо зарекомендовали себя в задачах численного моделирования, классификации и аппроксимации. В настоящий момент они находят все более широкое применение в различных областях науки и техники. Способность нейронных сетей к обучению обусловила их применение в системах распознавания изображений, обработки речи, построении прогностических моделей в экономике и др. [1,2].

В данной работе предложено применение нейронной сети с радиальными базисными функциями для решения задачи определения положения и ориентации металлического стержня на основании диаграммы обратного рассеивания. Данная проблема относится к классу обратных задач дифракции, когда по конфигурации отраженного поля необходимо определить геометрические и/или электриче- ские параметры рассеивателя [3]. Подобные задачи возникают в радиолокации при определении параметров цели, при детектировании металлических объектов, скрытых под слоем земли, или находящихся за диэлектрической стенкой и пр.

Отдельной проблемой при применении нейронных сетей в задачах распознавания, классификации и аппроксимации является построение вектора признаков на основании полученного сигнала. В данной работе применен подход выделения вектора энергетических признаков на основании вейвлет-пакетного разложения, который используется при распознавании геометрических текстур [4].

\section{РЕШЕНИЕ ЗАДАЧИ ДИФРАКЦИИ}

В настоящей работе рассмотрен случай рассеивания плоской гармонической волны идеально проводящим стержнем определен- 